\title{
Polymorphisms in the methylenetetrahydrofolate reductase (MTHFR) gene, intakes of folate and related $B$ vitamins and colorectal cancer: a case-control study in a population with relatively low folate intake
}

\author{
Linda Sharp ${ }^{1,2}$, Julian Little ${ }^{1,3}$, Nigel T. Brockton ${ }^{1,4}$, Seonaidh C. Cotton ${ }^{1,5}$, Lindsey F. Masson ${ }^{1,5}$, \\ Neva E. Haites ${ }^{1}$ and Jim Cassidy ${ }^{1,6}$ \\ ${ }^{1}$ Department of Medicine and Therapeutics, University of Aberdeen, Polwarth Building, Foresterhill, Aberdeen AB25 2ZD, UK \\ ${ }^{2}$ National Cancer Registry Ireland, Elm Court, Boreenmanna Road, Cork, Republic of Ireland \\ ${ }^{3}$ Canada Research Chair in Human Genome Epidemiology, Department of Epidemiology and Community Medicine, University of \\ Ottawa, Ottawa, Canada \\ ${ }^{4}$ Maternal and Child Health Sciences, University of Dundee, Ninewells Hospital and Medical School, Dundee DD1 9SY, UK \\ ${ }^{5}$ Department of Public Health, University of Aberdeen, Polwarth Building, Foresterhill, Aberdeen AB25 2ZD, UK \\ ${ }^{6}$ Beatson Oncology Centre, Western Infirmary, Glasgow G11 6NT, UK
}

(Received 16 October 2006 - Revised 21 May 2007 - Accepted 15 June 2007)

Folate is key in one-carbon metabolism, disruption of which can interfere with DNA synthesis, repair, and methylation. Efficient one-carbon metabolism requires other B vitamins and the optimal activity of enzymes including 5,10-methylenetetrahydrofolate reductase (MTHFR). We report a population-based case-control study of folate intake, related dietary factors and MTHFR polymorphisms (C677T, A1298C) and colorectal cancer in a population with relatively high colorectal cancer incidence and relatively low folate intake. A total of 264 cases with histologically confirmed incident colorectal cancer and 408 controls participated. There was no clear trend in risk with reported intakes of total, or dietary, folate, riboflavin, vitamin $\mathrm{B}_{12}$ or vitamin $\mathrm{B}_{6}$, nor were there interactions between folate intake and the other B vitamins or alcohol. For C677T, risk decreased with increasing variant alleles (multivariate $\mathrm{OR}$ for CT $v$. CC $=0.77$ (95\% CI 0.52, 1.16); OR for TT $v$. CC $=0.62(95 \% \mathrm{CI} 0.31$, 1.24)), which, although not statistically significant, was consistent with previous studies. For A1298C, compared with AA subjects, CC subjects had modest, non-significant, reduced risk (multivariate $\mathrm{OR}=0.81(95 \% \mathrm{CI} 0.45,1.49)$ ). There were significant interactions between total folate and C677T $(P=0.029)$ and A1298C $(P=0.025)$, and total vitamin $\mathrm{B}_{6}$ and both polymorphisms $(\mathrm{C} 677 \mathrm{~T}, P=0.016 ; \mathrm{A} 1298 \mathrm{C}, P=0.033)$, although the patterns observed differed from previous studies. Seen against the setting of low folate intake, the results suggest that the role of folate metabolism in colorectal cancer aetiology may be more complex than previously thought. Investigation of particular folate vitamers (for example, tetrahydrofolate, 5,10-methylenetetrahydrofolate) may help clarify carcinogenesis pathways.

Folate: MTHFR: Colorectal cancer: One-carbon metabolism

Folate, and its synthetic form, folic acid, is key in one-carbon metabolism, the disruption of which can interfere with DNA synthesis, repair and methylation. Low folate status or, more generally, low dietary methyl status (a combination of folate, methionine, alcohol and other B vitamins) may promote carcinogenesis. The mechanisms by which low folate could increase risk of malignancy include: (1) DNA hypomethylation and inappropriate activation of oncogenes ${ }^{1}$; and/ or (2) uracil misincorporation during DNA repair and synthesis, leading to DNA strand breaks, chromosome damage and, eventually, malignant transformation ${ }^{2}$. Higher reported folate intake has been associated with reduced colorectal cancer risk ${ }^{3}$. However, most studies have been conducted in populations where intake is relatively high, and a substantial proportion comes in the form of folic acid, either from supplements or through fortified foods; folic acid is more bioavailable than natural folates ${ }^{4}$.

Efficient one-carbon metabolism also requires riboflavin, vitamin $\mathrm{B}_{6}$, vitamin $\mathrm{B}_{12}$ and methionine. This raises the possibility that these factors, either on their own account, or by acting together with folate, might influence colorectal cancer risk. However, the available evidence is limited and/or inconsistent ${ }^{5}$.

One-carbon metabolism further requires the optimal activity of multiple enzymes, including 5,10-methylenetetrahydrofolate reductase (MTHFR), which directs the folate pool towards methylation or DNA repair. Several polymorphisms have been reported in the MTHFR gene, but only two have been investigated in relation to colorectal neoplasia - C677T and A1298C ${ }^{5}$. The $677 \mathrm{~T}$ variant lowers enzyme activity in vitro ${ }^{6}$ 
and has been associated with decreased plasma folate and vitamin $\mathrm{B}_{12}$ levels and raised homocysteine $\mathrm{f}^{7,8}$. In vitro studies suggest that low folate status may be required for this polymorphism to affect enzyme activity in vivo ${ }^{9,10}$. The functional impact of the $\mathrm{A} 1298 \mathrm{C}$ polymorphism is less clear ${ }^{5,11}$. In vitro enzyme activity appears to be reduced in homozygous variants and compound heterozygotes ${ }^{10,12,13}$, but the in vivo effects remain to be determined.

Most, but not all, previous studies have found reduced colorectal cancer risk in homozygotes for the variant C677T allele $^{5,14}$. A1298C has been less extensively investigated, and results have been inconsistent ${ }^{5,15}$. The inconsistencies may be due, in part, to differences in genotype distributions and folate intakes between populations.

The Scottish diet is distinguished by low vegetable intake ${ }^{16}$. This suggests folate levels may be relatively low, a view confirmed by the National Food Survey which revealed geographical variations in blood folate across Britain, with the lowest levels in Scotland ${ }^{17}$. The high alcohol intake ${ }^{18}$ and smoking prevalence ${ }^{19}$ may further compromise folate and, more generally, methyl status in the Scottish population. Furthermore, colorectal cancer incidence in Scotland is in the upper quarter of rates observed worldwide ${ }^{20}$.

We undertook a population-based case-control study in the north-east of Scotland to investigate whether intakes of folate and related dietary factors, and MTHFR polymorphisms, were associated with colorectal cancer risk in a population with a relatively low folate intake.

\section{Materials and methods}

\section{Ascertainment of cases and controls}

Eligible cases were resident in the Grampian Health Board region and diagnosed with a histological confirmed first primary invasive tumour of the colon or rectum between September 1998 and February 2000. They were identified each month from the computerised records of Aberdeen Royal Infirmary pathology laboratory, which provides the centralised service for Grampian.

Controls were selected from the Grampian Community Health Index, an inventory of everyone registered with a general practitioner. The Grampian Community Health Index has a high level of completeness for the Grampian population ${ }^{21}$. Each month, a pool of potential controls was selected at random, frequency matched to cases on age and sex. Individuals who declined to take part were replaced.

The study was approved by the Joint Ethical Committee of the University of Aberdeen and Grampian Health Board (Scotland, UK). All participants gave informed consent.

\section{Assessment of diet and other exposures}

With the permission of their general practitioner, subjects were recruited by post. They completed a questionnaire comprising a 150 -item semi-quantitative $\mathrm{FFQ}^{22}$ plus questions on a range of socio-demographic and lifestyle factors relevant to colorectal cancer aetiology. The FFQ had been validated in the local population ${ }^{23}$ and included questions on dietary supplement use in the reference period (approximately 1 year before completion).

\section{Genotyping}

Subjects provided a mouthwash sample. DNA was extracted from exfoliated buccal cells using the Elucigene CF12 protocol (Zeneca Diagnostics, Abingdon, Oxon, UK) and amplified by PCR. The amplification products were digested with HinfI

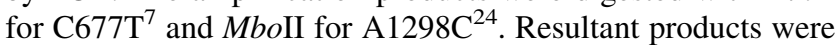
separated by electrophoresis through $3 \%$ (Metaphor $^{\circledR}$, FMC BioProducts) gels. Bands were visualised by ethidium bromide staining and UV transillumination.

Analyses were blind to case-control status. Each batch contained a negative (no template DNA) and two positive controls. Analyses were repeated if either amplification or digestion failed. Gels were double-read by two individuals and assays repeated for any samples considered ambiguous. Genotyping was also repeated, blind to the original results, for a $10 \%$ random selection ( $n$ 67) of samples; no differences were found compared with the originally assigned genotypes.

\section{Statistical analysis}

The dietary data were converted into estimated nutrient intakes using the UK national food composition tables, taking account of cereal fortification ${ }^{25}$. For seven subjects (three cases and four controls) the FFQ was not completed or was very incomplete. A further twelve subjects (six cases and six controls) were excluded on the basis of implausible total energy intakes $(<3347 \mathrm{~kJ} / \mathrm{d}$ for men or $<2092 \mathrm{~kJ} / \mathrm{d}$ for women ${ }^{26}$ or more than three standard deviations above mean intake in men and women separately). Protein intake was used as a surrogate for methionine. Dietary intakes were adjusted for total energy using the nutrient residual method ${ }^{26}$. For folate, vitamin $\mathrm{B}_{6}$, vitamin $\mathrm{B}_{12}$ and riboflavin, the primary analyses related to total intake, i.e. the sum of dietary (energy adjusted) and supplement intakes; secondary analyses related to dietary intake. Subjects were grouped into intake tertiles (for alcohol) or quartiles (other variables), based on the combined case and control distribution ${ }^{27}$, with the baseline group comprising non-consumers (alcohol) or the lowest quartile. For methyl content, the 'low' group comprised low total folate and protein $(<$ median) and high alcohol (upper two tertiles) and the 'high' group had high total folate and protein ( $\geq$ median) and low alcohol (no intake or lowest tertile).

For C677T and A1298C, separate and compound genotype was assigned. Hardy-Weinberg equilibrium was assessed in controls using Pearson's $\chi^{2}$. Association analyses were done for individual genotypes, and combining carriers of the variant alleles, taking homozygotes for the common allele as the reference group. In addition, to explore the impact of one variant in the absence of the other, risk estimates were computed for (i) C677T genotype among 1298AA carriers and (ii) A1298C genotypes among 677CC carriers. Logistic regression was used to compute adjusted and multivariate odds ratios (OR) and 95\% CI in Stata 8 (StataCorp LP, College Station, TX, USA). Adjusted OR were adjusted for sex, age and, for the dietary variables, total energy intake. Multivariate OR were further adjusted for potential confounders; factors which made a significant contribution (likelihood ratio test $P<0 \cdot 1$ ) were retained in 
the model. Trend tests ${ }^{28}$ were used to investigate doseresponse across dietary quantiles or by number of variant alleles. Effect modification was explored by computing OR for combinations of (i) intake variables and (ii) intake and genotype. The test for interaction was the change in deviance $(-2 \times \log$ likelihood) between a main-effects model and one including a cross-product term. All multivariate models were checked for adequate $\mathrm{fit}^{29}$.

\section{Results}

A total of 264 cases ( $62 \%$ of those eligible) and 408 controls (61\%) participated. Of the 264 cases, 189 cases had colon cancer and seventy-five rectal cancer (Table 1). Cases tended to be older than controls, and a higher proportion were men.

Median total folate intake was 299.7 (interquartile range 263.9-348.6) $\mu \mathrm{g} / \mathrm{d}$ (Table 2). Median dietary folate was 295 (interquartile range $261-332$ ) $\mu \mathrm{g} / \mathrm{d}$. Of the subjects, $9.5 \%$ (thirty-eight controls $(9.4 \%)$ and twenty-five cases $(9.6 \%)$ ) reported taking a supplement that contained folic acid. The majority (fifty-three out of sixty-three) took supplements that included $200 \mu \mathrm{g}$ folic acid.

For total folate intake, the multivariate OR exceeded unity for quartiles 2-4, but there was no clear trend (Table 2).

Table 1. Characteristics of study participants by case-control status (Numbers and percentages)

\begin{tabular}{|c|c|c|c|c|}
\hline \multirow[b]{2}{*}{ Factor } & \multicolumn{2}{|c|}{ Controls } & \multicolumn{2}{|c|}{ Cases } \\
\hline & $n$ & $\%^{*}$ & $n$ & $\%$ * \\
\hline \multicolumn{5}{|l|}{ Sex } \\
\hline Female & 198 & 48.5 & 114 & 43.2 \\
\hline Male & 210 & $51 \cdot 5$ & 150 & $56 \cdot 8$ \\
\hline \multicolumn{5}{|l|}{ Age (years)† } \\
\hline$<55$ & 101 & $24 \cdot 8$ & 23 & 8.7 \\
\hline $55-64$ & 127 & $31 \cdot 1$ & 60 & $22 \cdot 7$ \\
\hline $65-74$ & 111 & $27 \cdot 2$ & 91 & 34.5 \\
\hline 75 and older & 69 & $16 \cdot 9$ & 90 & $34 \cdot 1$ \\
\hline \multicolumn{5}{|l|}{ Tumour location } \\
\hline Colon & & & 189 & $71 \cdot 6$ \\
\hline Rectum & & & 75 & $28 \cdot 4$ \\
\hline \multicolumn{5}{|c|}{ First-degree family history of colorectal cancer } \\
\hline No & 371 & $91 \cdot 1$ & 214 & $81 \cdot 4$ \\
\hline Yes & 36 & 8.9 & 49 & $18 \cdot 6$ \\
\hline \multicolumn{5}{|l|}{ Social class $\ddagger$} \\
\hline I and II (non-manual) & 168 & $42 \cdot 6$ & 92 & $36 \cdot 2$ \\
\hline III (skilled manual) & 158 & $40 \cdot 1$ & 118 & $46 \cdot 5$ \\
\hline IV and V (unskilled manual) & 68 & $17 \cdot 3$ & 44 & $17 \cdot 3$ \\
\hline \multicolumn{5}{|l|}{ Country of birth } \\
\hline UK or Ireland & 385 & $96 \cdot 3$ & 252 & $98 \cdot 0$ \\
\hline Elsewhere & 15 & 3.7 & 5 & $2 \cdot 0$ \\
\hline \multicolumn{5}{|l|}{ Smoking status§ } \\
\hline Never smoked & 161 & $40 \cdot 4$ & 106 & $41 \cdot 3$ \\
\hline Ex-smoker & 164 & $41 \cdot 1$ & 114 & $44 \cdot 4$ \\
\hline Current smoker & 74 & $18 \cdot 6$ & 37 & $14 \cdot 4$ \\
\hline
\end{tabular}

* Percentage of those subjects with complete data for a particular factor.

† Age at diagnosis for cases and at pseudo date of diagnosis for controls (middle of month in which cases diagnosed).

‡Based on occupation at time questionnaire completed, or last occupation before retirement: for men and single women, based on own occupation; for women who were married, living as married, or widowed, based on occupation of husband or partner.

$\S$ At approximately 1 year before the completion of the questionnaire.
A similar pattern was observed for total riboflavin. There was a borderline significant association between protein intake and risk (global $P=0.055 ; P($ linear trend) $=0.066$ ), due to a one-third reduction in risk in the highest intake group. Compared with non-drinkers, disease risk was slightly, but non-significantly, raised for all categories of alcohol intake. The association was strongest in males (multivariate OR for $\mathrm{T} 1 v$. none $=1.58(95 \%$ CI $0.60,4.15)$; OR for T2 $v$. none $=1.57(95 \%$ CI $0.65,3.80)$; OR for $\mathrm{T} 3 v$. none $=1.72(95 \%$ CI $0.73,4.04))$. There was a suggestion of increasing risk with decreasing dietary methyl content, although the risk estimates were not statistically significant. There were no associations between total vitamin $B_{12}$ or vita$\min \mathrm{B}_{6}$ intakes and colorectal cancer.

Results of analyses restricted to dietary intake of folate, vitamin $\mathrm{B}_{12}$, vitamin $\mathrm{B}_{6}$ and riboflavin were similar to those for total intake, with slightly attenuated risk estimates (data not shown).

There was no evidence of interactions between total folate intake and total intake of vitamin $B_{12}$, vitamin $B_{6}$ or riboflavin, nor did particular combinations of alcohol and total folate influence risk (data not shown). Results were unchanged when analyses were repeated for dietary intake (data not shown).

The C677T genotype distribution among controls conformed with Hardy-Weinberg equilibrium $\quad\left(\chi_{1}^{2}=0.00\right.$; $P=0.999)$, but the A1298C distribution did not $\left(\chi_{1}^{2}=6.25\right.$; $P<0.05$ ); there was an excess of homozygous subjects (AA and $\mathrm{CC}$ ) and a deficit of heterozygotes. For C677T, risk decreased with increasing number of variant alleles (multivariate $\mathrm{OR}$ for $\mathrm{CT} v$. CC $=0.77$ (95\% CI $0.52,1.16)$; OR for TT $v$. $\mathrm{CC}=0.62(95 \%$ CI $0.31,1.24))$ but not significantly $(P($ linear trend $)=0 \cdot 103$; Table 3$)$. For A1298C, the risk for homozygous variant subjects was modestly, but not significantly, reduced (OR for $\mathrm{CC} v$. AA $=0.81$ (95\% CI 0.45 , 1.49)). As regards compound genotype, no subjects were homozygous for both variants, while four cases $(1.7 \%)$ and eleven controls $(2.8 \%)$ had three variant alleles. Compared with those with no variant alleles, individuals who were double heterozygous $(\mathrm{OR}=0.85$ (95\% CI $0.41,1.75)$ ) or homozygous variant $(\mathrm{OR}=0.71(95 \%$ CI $0.35,1.45))$ had slightly reduced risk. Among individuals who were 1298AA, multivariate OR for the C677T genotypes were: $1 \cdot 00,0.82$ (95\%CI 0.40, 1.67) and 0.77 (95\% CI 0.30, 1.93). Multivariate risk estimates for the $\mathrm{A} 1298 \mathrm{C}$ genotypes among individuals who were $677 \mathrm{CC}$ were: $1.00,1.41$ (95\% CI $0.67,2.96)$ and 0.75 (95\% CI $0.33,1.73)$.

There was a significant interaction between C677T and total folate $($ Table $4 ; P($ interaction $)=0 \cdot 029)$. Compared with $\mathrm{CC}$ individuals with low $(<$ median) intake, risk was significantly reduced in carriers of the variant allele with low intake (OR $=0.47(95 \%$ CI $0.27,0.83)$ ), with a less pronounced risk reduction in those with high intake. A significant interaction was found between total vitamin $\mathrm{B}_{6}$ intake and $\mathrm{C} 677 \mathrm{~T}$ $(P($ interaction $)=0.016)$, which followed a similar pattern to that for total folate. Repeating the analyses for dietary folate and vitamin $\mathrm{B}_{6}$ gave less pronounced risk estimates (data not shown).

There was a suggestion that C677T modified the associations between protein and alcohol intakes and colorectal cancer, although the tests for interaction were not statistically 
Table 2. Association between intake variables and colorectal cancer

(Numbers and percentages of subjects, $P$ values for likelihood ratio tests, odds ratios and $95 \%$ confidence intervals)

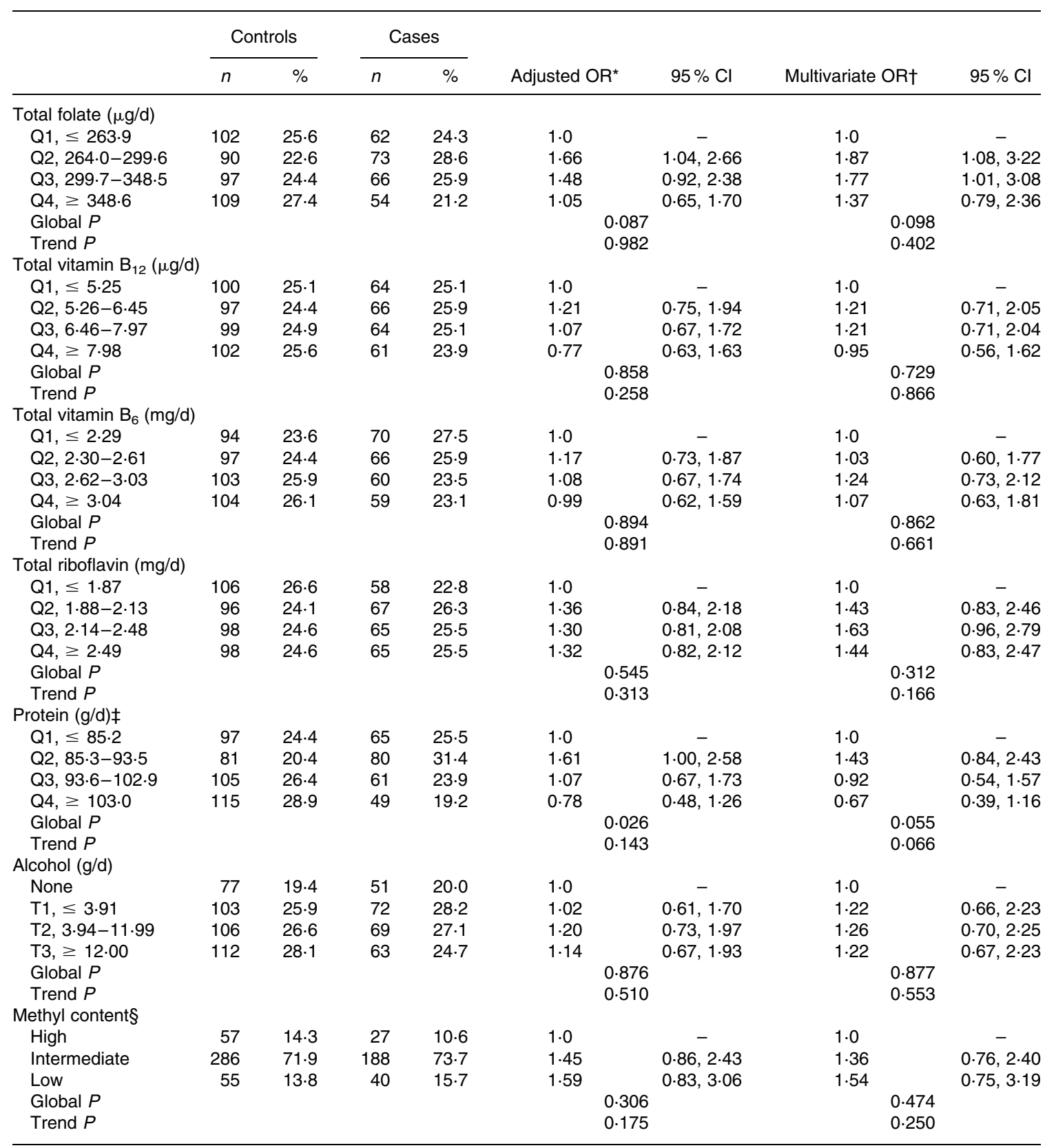

Q, quartile; T, tertile; NSAID, non-steroidal anti-inflammatory drugs

${ }^{*}$ Adjusted for age, sex and total energy.

†All models adjusted for sex, age, total energy, physical activity, family history of colorectal cancer, regular use of any NSAID, sex $\times$ NSAID interaction term; model for protein also adjusted for type of dietary supplement; model for alcohol also adjusted for type of dietary supplement and protein.

$\ddagger$ Protein from food only.

\$High methyl content is high total folate, high protein and either no alcohol intake or intake in T1; low methyl status is low total folate, low protein and alcohol in upper two tertiles; intermediate is all other combinations of total folate, protein and alcohol. High folate or protein is intake in upper two quartiles; low folate or protein is intake in lower two quartiles.

significant. There were no interactions between C677T and either vitamin $B_{12}$ or riboflavin.

A significant interaction was observed between total folate and A1298C (Table 5; $P$ (interaction) $=0.025)$. The group at lowest risk comprised homozygotes for the wild-type allele with low intake. Compared with this group, those with the $\mathrm{AC} / \mathrm{CC}$ genotype and low intake or AA genotype and high intake had significantly raised risk $(\mathrm{OR}=1.75(95 \%$ CI $1.00,3.10)$ and OR $=1.91(95 \%$ CI $1.05,3.50)$ respectively). Similar patterns were apparent for dietary folate (data not shown; $P($ interaction $)=0.060$ ) and total (Table 5; $P($ interaction $)=0.033)$ and dietary vitamin $\mathrm{B}_{6} \quad$ (data not shown; $P($ interaction $)=0.053)$. A1298C did not modify the relationships between colorectal cancer and vitamin $\mathrm{B}_{12}$ or 
Table 3. Association between methylenetetrahydrofolate reductase (MTHFR) genotype and colorectal cancer

(Numbers and percentages of subjects, $P$ values for likelihood ratio tests, odds ratios and $95 \%$ confidence intervals)

\begin{tabular}{|c|c|c|c|c|c|c|c|c|}
\hline & \multicolumn{2}{|c|}{ Controls } & \multicolumn{2}{|c|}{ Cases } & \multirow[b]{2}{*}{ Adjusted OR* } & \multirow[b]{2}{*}{$95 \% \mathrm{Cl}$} & \multirow[b]{2}{*}{ Multivariate $\mathrm{OR} \dagger$} & \multirow[b]{2}{*}{$95 \% \mathrm{Cl}$} \\
\hline & $n$ & $\%$ & $n$ & $\%$ & & & & \\
\hline \multicolumn{9}{|l|}{ C677T‡ } \\
\hline Homozygous wild type (CC) & 170 & $43 \cdot 2$ & 117 & $46 \cdot 6$ & $1 \cdot 0$ & - & $1 \cdot 0$ & - \\
\hline Heterozygous (CT) & 177 & 44.9 & 111 & $44 \cdot 2$ & 0.91 & $0.64,1.29$ & 0.77 & $0.52,1.16$ \\
\hline Homozygous variant (TT) & 47 & 11.9 & 23 & $9 \cdot 2$ & 0.75 & $0.42,1.34$ & 0.62 & $0.31,1.24$ \\
\hline Global $P$ & & & & & \multicolumn{2}{|c|}{0.603} & \multicolumn{2}{|l|}{0.264} \\
\hline Trend $P$ & & & & & \multicolumn{2}{|c|}{0.329} & \multicolumn{2}{|l|}{$0 \cdot 103$} \\
\hline Heterozygous/homozygous variant (CT/TT)§ & 224 & $56 \cdot 9$ & 134 & $53 \cdot 4$ & 0.88 & $0.63,1.22$ & 0.75 & $0.51,1.09$ \\
\hline Global $P$ & & & & & \multicolumn{2}{|c|}{0.441} & \multicolumn{2}{|l|}{0.134} \\
\hline \multicolumn{9}{|l|}{$\mathrm{A} 1298 \mathrm{C} \|$} \\
\hline Homozygous wild type (AA) & 177 & 44.9 & 105 & 42.9 & 1.0 & - & 1.0 & - \\
\hline Heterozygous (AC) & 157 & $39 \cdot 9$ & 111 & $45 \cdot 3$ & $1 \cdot 18$ & $0.82,1.69$ & $1 \cdot 21$ & $0.80,1.84$ \\
\hline Homozygous variant (CC) & 60 & $15 \cdot 2$ & 29 & $11 \cdot 8$ & 0.67 & $0.39,1 \cdot 13$ & 0.81 & $0.45,1.49$ \\
\hline Global $P$ & & & & & \multicolumn{2}{|c|}{0.100} & \multicolumn{2}{|l|}{0.375} \\
\hline Trend $P$ & & & & & \multicolumn{2}{|c|}{0.391} & \multicolumn{2}{|l|}{0.843} \\
\hline Heterozygous/homozygous variant $(\mathrm{AC} / \mathrm{CC}) \S$ & 217 & $55 \cdot 1$ & 140 & $57 \cdot 1$ & 1.03 & $0.73,1.44$ & $1 \cdot 10$ & $0.72,1.63$ \\
\hline Global $P$ & & & & & \multicolumn{2}{|c|}{0.879} & \multicolumn{2}{|l|}{0.632} \\
\hline \multicolumn{9}{|l|}{ Compound genotype } \\
\hline Homozygous wild type (CC and $\mathrm{AA})$ & 43 & $11 \cdot 1$ & 26 & $10 \cdot 7$ & $1 \cdot 0$ & - & $1 \cdot 0$ & - \\
\hline Single heterozygous (CT or $\mathrm{AC}$ ) & 166 & $42 \cdot 9$ & 117 & $48 \cdot 4$ & $1 \cdot 21$ & $0.68,2 \cdot 13$ & 1.08 & $0.57,2.06$ \\
\hline Double heterozygous (CT and $A C$ ) & 74 & $19 \cdot 1$ & 48 & $19 \cdot 8$ & 1.02 & $0.54,1.93$ & 0.85 & $0.41,1.75$ \\
\hline Homozygous variant (TT or CC) & 104 & $26 \cdot 9$ & 51 & $21 \cdot 1$ & 0.74 & $0.40,1.38$ & $0 \cdot 71$ & $0.35,1.45$ \\
\hline Global $P$ & & & & & \multicolumn{2}{|c|}{0.176} & \multicolumn{2}{|l|}{0.412} \\
\hline Trend $P$ & & & & & \multicolumn{2}{|c|}{0.076} & \multicolumn{2}{|l|}{0.129} \\
\hline Up to one variant allele ${ }^{\star \star}$ & 209 & $54 \cdot 0$ & 143 & $59 \cdot 1$ & 1.0 & - & $1 \cdot 0$ & - \\
\hline Two or more variant allelest† & 178 & $46 \cdot 0$ & 99 & $40 \cdot 9$ & 0.74 & $0.52,1.04$ & 0.73 & $0.49,1.08$ \\
\hline Global $P$ & & & & & \multicolumn{2}{|c|}{0.078} & \multicolumn{2}{|l|}{0.115} \\
\hline
\end{tabular}

NSAID, non-steroidal anti-inflammatory drugs.

${ }^{*}$ Adjusted for age and sex.

†Adjusted for sex, age, family history of colorectal cancer, physical activity, regular use of any NSAID, sex $\times$ NSAID interaction term, total energy intake and type of dietary supplements.

$\ddagger$ Three cases did not provide a mouthwash sample; genotyping failed for ten cases and fourteen controls.

$\S$ OR for carriers of variant allele $v$. homozygous wild-types.

॥Three cases did not provide a mouthwash sample; genotyping failed for sixteen cases and fourteen controls.

I Three cases did not provide a mouthwash sample; compound genotype could not be assigned for nineteen cases and twenty-one controls because genotyping for either C677T or A1298C had failed.

** Includes homozygous wild type for both polymorphisms or heterozygote for either polymorphism.

†† Includes heterozygotes for both polymorphisms or homozygous variant for either; OR for two or more variant alleles $v$. zero or one variant allele.

riboflavin, either for total (Table 5) or dietary intake (data not shown). There were no significant interactions between A1298C and protein or alcohol.

\section{Discussion}

\section{Strengths and limitations}

The major strength of the study was the population basis, with both cases and control recruited from population-based sampling frames. The participation rate was similar to another UK study in which contact was made by post ${ }^{30}$. Other than refusal, the main reasons for non-participation among cases were death ( $n 37 ; 8.7 \%$ of those eligible) or general practitioner refusal $(n 15 ; 3.5 \%)$, primarily because subjects were deemed to be too ill to approach. For controls, the general practitioner refused permission to approach sixteen individuals and a further eight had died $(3.6 \%$ in total). Eligible male cases were significantly more likely to participate than females; controls resident in urban areas were significantly less likely to take part ${ }^{31}$. Deprivation category of residence was not significantly associated with participation among either cases or controls. Analysis of known colorectal cancer risk factors resulted in associations consistent with previous evidence $^{32}$.

Of the controls, $12 \%$ were $677 \mathrm{TT}$ homozygotes, consistent with the frequency in other white and northern European populations $^{33}$. Of the controls, $15 \%$ carried the $1298 \mathrm{CC}$ genotype, slightly higher than the prevalence in most European studies 5 , but consistent with another study in the same area $(18 \% \text { CC })^{34}$. The A1298C genotype frequencies were not in Hardy-Weinberg equilibrium. Since subjects were unaware of the study hypotheses or their genotype, differential participation by genotype seems unlikely. Moreover, the genotyping followed rigorous quality-control measures, which should help guard against systematic errors $^{35}$. Other potential explanations for a departure from Hardy-Weinberg equilibrium include non-random mating, genetic drift and chance.

The FFQ was developed and extensively validated in the local area. For folate, alcohol and riboflavin, high levels of agreement (rank correlation coefficients 0.55-0.79) were found when comparing questionnaire responses with $4 \mathrm{~d}$ weighed records ${ }^{23}$.

The case-control design is potentially susceptible to the effects of recall bias in the assessment of lifestyle (but not 
Table 4. Interactions between methylenetetrahydrofolate reductase (MTHFR) C677T genotype and dietary variables*

(Odds ratios, $95 \%$ confidence intervals, and $P$ values for tests for interaction)

\begin{tabular}{|c|c|c|c|c|c|c|c|c|}
\hline \multirow{2}{*}{$\begin{array}{l}\text { C677T genotype... } \\
\text { Dietary factor }\end{array}$} & \multicolumn{2}{|c|}{$\mathrm{CC}$} & \multicolumn{2}{|c|}{$\mathrm{CT} / \mathrm{TT}$} & \multicolumn{2}{|l|}{$\mathrm{CC}$} & \multicolumn{2}{|c|}{$\mathrm{CT} / \mathrm{TT}$} \\
\hline & Adjusted OR† & $95 \% \mathrm{Cl}$ & Adjusted OR† & $95 \% \mathrm{Cl}$ & Multivariate OR $\ddagger$ & $95 \% \mathrm{Cl}$ & Multivariate OR & $95 \% \mathrm{Cl}$ \\
\hline \multicolumn{9}{|l|}{ Total folate } \\
\hline Low & $1 \cdot 0$ & - & 0.61 & $0.37,0.99$ & $1 \cdot 0$ & - & 0.47 & $0.27,0.83$ \\
\hline High & 0.69 & $0.41,1 \cdot 14$ & 0.87 & $0.41,1.14$ & 0.75 & $0.43,1.32$ & 0.84 & $0.49,1.43$ \\
\hline$P$ (interaction) & \multicolumn{4}{|c|}{0.037} & \multicolumn{4}{|c|}{0.029} \\
\hline \multicolumn{9}{|l|}{ Total vitamin $\mathrm{B}_{12}$} \\
\hline Low & $1 \cdot 0$ & - & 1.07 & $0.67,1.73$ & 1.0 & - & 0.89 & $0.52,1.52$ \\
\hline High & 1.22 & $0.74,2.02$ & 0.87 & $0.54,1.39$ & 1.21 & $0 \cdot 70,2 \cdot 11$ & 0.75 & $0.43,1.28$ \\
\hline$P$ (interaction) & \multicolumn{4}{|c|}{0.233} & \multicolumn{4}{|c|}{0.347} \\
\hline \multicolumn{9}{|l|}{ Total vitamin $B_{6}$} \\
\hline Low & $1 \cdot 0$ & - & 0.62 & $0.38,1.00$ & 1.0 & - & 0.45 & $0.26,0.79$ \\
\hline High & 0.68 & $0.41,1.12$ & 0.84 & $0.53,1.35$ & 0.71 & $0.41,1.24$ & 0.83 & $0.49,1.39$ \\
\hline$P$ (interaction) & \multicolumn{4}{|c|}{0.046} & \multicolumn{4}{|c|}{0.016} \\
\hline \multicolumn{9}{|l|}{ Total riboflavin } \\
\hline Low & $1 \cdot 0$ & - & 0.84 & $0.51,1.36$ & $1 \cdot 0$ & - & 0.64 & $0.36,1 \cdot 12$ \\
\hline High & $1 \cdot 13$ & $0.68,1.87$ & 1.03 & $0.63,1.67$ & 1.19 & $0.68,2.09$ & 1.01 & $0.59,1.74$ \\
\hline$P$ (interaction) & \multicolumn{4}{|c|}{0.805} & \multicolumn{4}{|c|}{0.472} \\
\hline \multicolumn{9}{|l|}{ Protein } \\
\hline Low & 1.0 & - & 1.07 & $0.66,1.71$ & 1.0 & - & 0.87 & $0.51,1.48$ \\
\hline High & 0.97 & $0.59,1.59$ & 0.69 & $0.43,1 \cdot 12$ & 0.88 & $0.50,1.53$ & 0.55 & $0.32,0.97$ \\
\hline$P$ (interaction) & \multicolumn{4}{|c|}{0.249} & \multicolumn{4}{|c|}{0.419} \\
\hline \multicolumn{9}{|l|}{ Alcohol } \\
\hline Low & 1.0 & - & 0.65 & $0.40,1.07$ & 1.0 & - & 0.55 & $0.31,0.98$ \\
\hline High & 0.79 & $0.47,1.33$ & 0.91 & $0.55,1.50$ & 0.76 & $0.42,1.38$ & 0.73 & $0.40,1.32$ \\
\hline$P$ (interaction) & \multicolumn{4}{|c|}{0.106} & \multicolumn{4}{|c|}{0.16} \\
\hline \multicolumn{9}{|l|}{ Methyl content } \\
\hline High or intermediate & $1 \cdot 0$ & - & 0.86 & $0.60,1.25$ & 1.0 & - & 0.73 & $0.48,1.11$ \\
\hline Low & 1.01 & $0.51,2.00$ & 0.93 & $0.46,1.89$ & 1.02 & $0.47,2 \cdot 20$ & 0.89 & $0.40,1.99$ \\
\hline$P$ (interaction) & \multicolumn{4}{|c|}{0.902} & \multicolumn{4}{|c|}{0.748} \\
\hline
\end{tabular}

NSAID, non-steroidal anti-inflammatory drugs.

${ }^{*}$ Folate, vitamin $\mathrm{B}_{12}$, vitamin $\mathrm{B}_{6}$, riboflavin and protein categorised at median intake; low alcohol intake is no intake or lowest tertile while high intake is intake in upper two tertiles; high methyl content is high total folate, high protein and either no alcohol intake or intake in first tertile, low methyl status is low total folate, low protein and alcohol in upper two tertiles, intermediate is all other combinations of total folate, protein and alcohol; protein based on intake from food sources.

$\dagger$ Adjusted for age, sex and total energy intake.

$\ddagger$ All models adjusted for age, sex, total energy intake, family history of colorectal cancer, physical activity, regular use of any NSAID; model for protein also adjusted for type of dietary supplements; models for alcohol and methyl content also adjusted for type of dietary supplements and sex $\times$ NSAID interaction term.

genetic) risk factors. Other than this, the main limitation was limited power both for main effects and, in particular, for interactions. As regards main effects, for a genetic variant occurring in $12 \%$ of the population (i.e. MTHFR TT) the study had $80 \%$ power to detect an OR of 0.45 or less ( $\alpha=0.05$; two-sided test); this OR is in the region of the risk estimates reported in previous studies $^{36}$. It should be borne in mind that a relatively large number of statistical tests were conducted, and a proportion of positive results would be expected by chance.

Ethnic group was not assessed, but only $3 \%$ of subjects were born outside the UK or Ireland $(78 \%$ born in Scotland; $17 \%$ elsewhere in the UK or Ireland). In the 2001 census for Scotland, $98 \%$ of the population described themselves as 'white' (Scottish, British, Irish or other) and $2 \%$ as southeast Asian, Chinese or black ${ }^{37}$. Thus it seems unlikely that the results were adversely affected by population stratification, which needs to be quite extreme to have a major impact ${ }^{38}$.

\section{Folate and other intake variables}

Unlike most previous studies ${ }^{3}$, we did not find an inverse relationship between total folate intake and colorectal cancer. In contrast, compared with the lowest intake quartile, risk estimates for the other quartiles exceeded unity, and followed a bell-shaped pattern. A similar pattern has been reported between plasma folate and colorectal cancer in a prospective study from Sweden ${ }^{39}$. When our analysis was restricted to subjects who did not use folic acid-containing supplements, the pattern persisted (multivariate OR: 1.0, $1.86(95 \%$ CI $1.07,3.22), 1.82$ (95\% CI 1.03, 3.19) and 0.96 (95\% CI $0.51,1.79)$ ). Although some previous studies have found the inverse relationship to be stronger for colon than rectal tumours ${ }^{40,41}$, when we stratified by site, there was no clear evidence of a trend with colon or rectal cancer. Although there may be substantial error in assessment of dietary folate intakes ${ }^{42}$ and supplement use $\mathrm{e}^{43}$, the resulting misclassification is most probably random, and would be unlikely to produce the observed result.

In further analyses, in women we found a modest, albeit non-significant, reduced risk in the highest total folate group (age- and sex-adjusted OR for quartile $4 v$. quartile $1=0.73$ (95\% CI 0.35, 1.52)). Several other case-control studies found that the association between colorectal neoplasia and folate (as intake or from supplements) was only evident, or was stronger, amongst females ${ }^{44-48}$. Folic acid supplement use is reported to be higher in women ${ }^{49}$. In the present study, $11.6 \%$ of females and $7.6 \%$ of males used folic acidcontaining supplements. These findings raise the possibility that folate status (or bioavailable folate, at least) may be 
Table 5. Interactions between methylenetetrahydrofolate reductase (MTHFR) A1298C genotype and dietary variables*

(Odds ratios, $95 \%$ confidence intervals, and $P$ values for tests for interaction)

\begin{tabular}{|c|c|c|c|c|c|c|c|c|}
\hline \multirow{2}{*}{$\begin{array}{l}\text { A1298C genotype... } \\
\text { Dietary factor }\end{array}$} & \multicolumn{2}{|c|}{$\mathrm{AA}$} & \multicolumn{2}{|c|}{$\mathrm{AC} / \mathrm{CC}$} & \multicolumn{2}{|l|}{ AA } & \multicolumn{2}{|c|}{$\mathrm{AC} / \mathrm{CC}$} \\
\hline & Adjusted OR† & $95 \% \mathrm{Cl}$ & Adjusted OR $†$ & $95 \% \mathrm{Cl}$ & Multivariate OR $\ddagger$ & $95 \% \mathrm{Cl}$ & Multivariate OR & $95 \% \mathrm{Cl}$ \\
\hline \multicolumn{9}{|l|}{ Total folate } \\
\hline Low & 1.0 & - & $1 \cdot 70$ & $1 \cdot 04,2 \cdot 78$ & 1.0 & - & 1.75 & $1.00,3 \cdot 10$ \\
\hline High & 1.62 & $0.96,2.73$ & 1.07 & $0.65,1.78$ & 1.91 & $1.05,3.50$ & 1.37 & $0.78,2.41$ \\
\hline$P$ (interaction) & \multicolumn{4}{|c|}{0.007} & \multicolumn{4}{|c|}{0.025} \\
\hline \multicolumn{9}{|l|}{ Total vitamin $B_{12}$} \\
\hline Low & 1.0 & - & 0.98 & $0.60,1.60$ & 1.0 & - & 1.09 & $0.63,1.89$ \\
\hline High & 0.89 & $0.53,1.49$ & 1.03 & $0.63,1.66$ & 1.01 & $0.56,1.83$ & 1.14 & $0.66,1.96$ \\
\hline$P$ (interaction) & \multicolumn{4}{|c|}{0.64} & \multicolumn{4}{|c|}{0.943} \\
\hline \multicolumn{9}{|l|}{ Total vitamin $B_{6}$} \\
\hline Low & 1.0 & - & 1.43 & $0 \cdot 88,2 \cdot 32$ & 1.0 & - & $1 \cdot 71$ & $0.97,3.01$ \\
\hline High & 1.30 & $0.77,2.19$ & 1.03 & $0.63,1.68$ & 1.82 & $0.99,3.33$ & 1.32 & $0.76,2.29$ \\
\hline$P$ (interaction) & \multicolumn{4}{|c|}{0.092} & \multicolumn{4}{|c|}{0.033} \\
\hline \multicolumn{9}{|l|}{ Total riboflavin } \\
\hline Low & 1.0 & - & 1.04 & $0.63,1.70$ & 1.0 & - & $1 \cdot 11$ & $0.63,1.95$ \\
\hline High & $1 \cdot 14$ & $0.68,1.91$ & $1 \cdot 22$ & $0.76,1.95$ & 1.42 & $0.78,2.58$ & 1.49 & $0.87,2.54$ \\
\hline$P$ (interaction) & \multicolumn{4}{|c|}{0.950} & \multicolumn{4}{|c|}{0.891} \\
\hline \multicolumn{9}{|l|}{ Protein } \\
\hline Low & 1.0 & - & 0.87 & $0.54,1.41$ & 1.0 & - & $1 \cdot 28$ & $0.74,2.22$ \\
\hline High & 0.58 & $0.34,0.98$ & 0.78 & $0.49,1.26$ & 0.82 & $0.45,1.52$ & 0.81 & $0.47,1.39$ \\
\hline$P($ interaction $)$ & \multicolumn{4}{|c|}{0.216} & \multicolumn{4}{|c|}{0.518} \\
\hline \multicolumn{9}{|l|}{ Alcohol } \\
\hline Low & $1 \cdot 0$ & - & 1.44 & $0.88,2 \cdot 37$ & 1.0 & - & 1.55 & $0.87,2.76$ \\
\hline High & 1.50 & $0.87,2.58$ & $1 \cdot 20$ & $0.72,2.01$ & 1.54 & $0.82,2.89$ & $1 \cdot 25$ & $0.69,2.25$ \\
\hline$P$ (interaction) & \multicolumn{4}{|c|}{0.674} & \multicolumn{3}{|c|}{0.106} & \\
\hline \multicolumn{9}{|l|}{ Methyl content } \\
\hline High or intermediate & 1.0 & - & 1.06 & $0.73,1.54$ & 1.0 & - & 1.02 & $0.67,1.55$ \\
\hline Low & $1 \cdot 15$ & $0.52,2.53$ & $1 \cdot 23$ & $0.65,2.30$ & $1 \cdot 11$ & $0.45,2.74$ & 1.46 & $0.72,2.95$ \\
\hline$P($ interaction $)$ & \multicolumn{4}{|c|}{0.986} & \multicolumn{4}{|c|}{0.658} \\
\hline
\end{tabular}

NSAID, non-steroidal anti-inflammatory drugs.

${ }^{*}$ Folate, vitamin $\mathrm{B}_{12}$, vitamin $\mathrm{B}_{6}$, riboflavin and protein categorised at median intake; low alcohol intake is no intake or lowest tertile while high intake is intake in upper two tertiles; high methyl content is high total folate, high protein and either no alcohol intake or intake in first tertile, low methyl content is low total folate, low protein and alcohol in upper two tertiles, intermediate is all other combinations of total folate, protein and alcohol; protein based on intake from food sources.

† Adjusted for age, sex and total energy intake.

$\ddagger$ All models (except methyl content) adjusted for sex, age, total energy, family history of colorectal cancer, physical activity, regular use of any NSAID and sex $\times$ NSAID interaction term; models for protein and alcohol also adjusted for type of dietary supplements; model for methyl content adjusted for sex, age, total energy, family history of colorectal cancer, physical activity, regular use of any NSAID and type of dietary supplements.

higher for females than males for the same intake; we are not, however, aware of any evidence confirming this. There may also be a differential effect by sex on folate status of other factors influencing dietary methyl content. For example, men are more likely to drink alcohol, and to consume greater quantities, than women ${ }^{48}$; in the present study, $74 \%$ of females and $86 \%$ of males consumed alcohol. Similarly, methionine intake can be very different, possibly because men are likely to eat greater quantities of red meat ${ }^{50}$. Alternatively, folate intake estimates among women may be subject to less measurement error. In the validation of the FFQ used in the present study, for most nutrients the agreement between questionnaire estimates and weighed records was higher for females than males ${ }^{23}$.

The median dietary folate intake among controls $(295 \mu \mathrm{g} / \mathrm{d})$ was close to population estimates (average intake from food and drink $274 \mu \mathrm{g} / \mathrm{d}^{51}$ ). In the USA, by contrast, a large proportion of the population meets the recommended intake of $400 \mu \mathrm{g} / \mathrm{d}^{52}$. The proportion of controls taking folic acid-containing supplements $(<10 \%)$ is typical of the UK population $^{53}$, but considerably lower than in the USA ${ }^{48,49,54}$. The range of total intake in the present study was relatively narrow; cut-off points for the lowest and highest quartiles were 264 and $349 \mu \mathrm{g} / \mathrm{d}$. This contrasts with several previous studies in which the cut-off point for the highest quantile was $>600 \mu \mathrm{g} / \mathrm{d}^{50,55-57}$. Moreover, in most previous studies, including those where average intake was lower than in the $\mathrm{USA}^{58,59}$, there was greater variability in intake than in the present study. It is noteworthy that in the prospective study in Sweden which reported a bell-shaped relationship between plasma folate and colorectal cancer ${ }^{39}$ - similar to our finding for folate intake - the plasma folate concentrations were considerably lower than in prospective studies from the USA that found inverse relationships with plasma or serum folate ${ }^{36,56}$. Van Guelpen et al. concluded that the low folate status of their study population may have precluded detection of a protective effect of high plasma folate concentrations ${ }^{39}$. A similar conclusion holds for the present study (i.e. the generally low intake, and narrow range, meant that a protective effect of higher intakes could not be found). Further, in view of the weight of evidence in this area, it seems most likely that the increased risk observed for intermediate intakes is due to chance.

The lack of statistical interaction between folate and alcohol is compatible with most previous studies ${ }^{57-60}$. Although some studies have suggested that the risk reduction associated with 
high folate intake was confined to those with low methionine intake $e^{55,59}$, we found no interaction between folate and protein (as a marker for methionine). There is tension in the previous evidence, however, in that the pattern of the folate-methionine interaction is not consistent with what would be expected on the basis of the low-methyl diet hypothesis: according to this, the combination of low intakes of folate and methionine together with high alcohol should increase disease risk. The modest raised risk we observed for intermediate and low dietary methyl content is broadly consistent with previous studies $^{48,50,58,60}$. The extent to which the effect of the 'methyl diet' on disease risk exceeds that of folate alone remains unclear, however.

\section{Effects of genotype}

In most previous studies, carriers of three variant alleles, if they have occurred at all, have been rare ${ }^{5}$. Our frequencies of $2.8 \%$ among controls and $1.7 \%$ among cases are quite high but are, of course, based on very small numbers of individuals. The high frequency, which appears to occur mainly in UK and Canadian populations, may be due to a founder effect ${ }^{61}$.

The moderate risk reduction, and dose-response, associated with the $677 \mathrm{~T}$ allele, although not statistically significant, is compatible with most previous studies ${ }^{5,14}$. As regards A1298C, eight of eleven studies found lower risk for the variant allele $^{15}$, although not all reached significance and an effect was not seen in all subgroups. Our modest, non-significant, reduced risk in CC subjects is consistent with this.

In common with previous investigators ${ }^{36,62,63}$, we found a significant interaction between folate and C677T. However, the pattern of interaction differed from that reported previously due, in part, to differences in the folate main effect. In addition, for reasons of statistical power, we combined CT and TT genotypes in the analysis. This would have concealed the low risk in TT subjects with high folate (or dietary methyl content) that has been reported elsewhere ${ }^{36,62,64}$. Although we observed a significant folate-A1298C interaction, previous studies have been inconsistent ${ }^{54,63,65}$. There is linkage disequilibrium between C677T and A1298C. In the present study, sixty of the sixty-eight individuals with the 677TT genotype also carried 1298AA, while seventy-nine of the eighty-seven who were $1298 \mathrm{CC}$ also carried 677CC. This meant that there was considerable overlap between the sub-groups at lowest risk in the two interaction analyses (C677T: low folate and CT/TT genotype; A1298C: low folate and AA genotype), which explains, in part, the different patterns of interaction observed for the two polymorphisms. More generally, differences in patterns of linkage disequilibrium between populations may contribute to heterogeneity between studies ${ }^{66}$.

The less consistent findings for A1298C, than C677T, regarding colorectal cancer could also be because A1298C appears to have less strong functional effects, although it should be noted that the functional evidence is limited and the in vitro and in vivo impact of the variant allele is not fully resolved ${ }^{5,11}$. In analyses of 199 controls from the present study, plasma and erythrocyte folate (measured by the microbiological assay) levels were significantly lower, and plasma homocysteine levels significantly higher, in 677TT than CC individuals, while the A1298C variant was not associated with folate or homocysteine levels ${ }^{67}$. Neither polymorphism was related to levels of various biomarkers of DNA stability measured in lymphocytes, including strand breaks, misincorporated uracil or global methylation. The evidence from other similar studies on MTHFR and DNA stability is inconsistent $^{68-72}$. One reason for this may be that these studies, and those of intake, are not assessing folate status in the relevant tissue. What may be important is localised (rather than systemic) folate depletion acting in concert with $\mathrm{C} 677 \mathrm{~T}^{11}$. Current knowledge on folate status in colonic tissue is limited. For example, the extent to which colonic folate concentrations vary between individuals, or along the colon within a single individual, or correlate with levels in lymphocytes or dietary intakes, is not clear.

The significant interactions between vitamin $\mathrm{B}_{6}$ and MTHFR genotype followed a similar pattern and had risk estimates similar to those for folate. This may reflect the fact that dietary sources for the two nutrients overlap substantially; after adjusting for total energy intake the correlation between folate and vitamin $\mathrm{B}_{6}$ exceeded 0.70.

Some investigators have reported an alcohol-C677T interaction, such that higher alcohol intake abolished the reduced disease risk associated with the TT genotype ${ }^{36,54,62}$. The present results suggested effect modification, but were not significant. The median alcohol intake among consumers was lower than the 'high' intake groups in previous studies (present study, $3.9 \mathrm{~g} / \mathrm{d}$ (about 0.5 units $/ \mathrm{d}$ ); Chen et $a .^{62}$, $\geq$ five drinks/week; Ma et al. ${ }^{36}, \geq$ one drink/d).

Most previous studies of folate and folate-MTHFR interactions have been conducted in populations where intake is relatively high, and a substantial proportion comes in the form of folic acid. The results of the present study, undertaken in a population with relatively low folate intake, suggest that the role of folate metabolism in colorectal cancer aetiology may be even more complex than previously thought. The challenge now is to unravel this complexity. 5,10MTHFR irreversibly converts 5,10-methylenetetrahydrofolate to 5-methyltetrahydrofolate, the former vital for DNA synthesis and the latter key in DNA methylation. Thus, the C677T polymorphism alters the distribution of erythrocyte folates $^{73}$, suggesting that particular folate species might be important in colorectal cancer. The direction of the MTHFR-colorectal cancer association - which is the opposite of that expected a priori ${ }^{5}$ - suggests that the availability of tetrahydrofolate and 5,10-methylenetetrahydrofolate may be particularly pertinent. This is supported by a study in colorectal tumour tissue, which found that 677TT patients had significantly lower concentrations of tetrahydrofolate and 5,10-methylenetetrahydrofolate ${ }^{74}$. Expansion of the evidence on individual folate species with regard to: (1) distribution in the diet, blood and other bodily tissues in different populations; (2) factors that influence intracellular distribution and availability; and (3) disease risk, might help advance understanding of folate metabolism in colorectal neoplasia and, ultimately, shed light on carcinogenesis pathways.

\section{Acknowledgements}

The present study was funded by a grant from the National Hospitals Trust. We thank Janet Kyle, Margaret Smith, Martine Barnes and Jennifer Grzybowski for assistance with 
data entry and David Grubb for processing the FFQ. Graeme McHardy and Diane Thom kindly provided downloads of cases and controls. Rachel Melvin, Joanne Tomany and Mhairi Gilmour assisted with compiling data on the content of dietary supplements.

\section{References}

1. Kim Y-I (2004) Folate and DNA methylation: a mechanistic link between folate deficiency and colorectal cancer? Cancer Epidemiol Biomarkers Prev 13, 511-519.

2. Ames BN (2001) DNA damage from micronutrient deficiencies is likely to be a major cause of cancer. Mutat Res 475, 7-20.

3. Sanjoaquin MA, Allen N, Couto E, Roddam AW \& Key TJ (2005) Folate intake and colorectal cancer risk: a meta-analytical approach. Int $J$ Cancer 113, 825-828.

4. Sauberlich HE, Kretsch MJ, Skala JH, Johnson HL \& Taylor PC (1987) Folate requirement and metabolism in nonpregnant women. Am J Clin Nutr 46, 1016-1028.

5. Sharp L \& Little J (2004) Polymorphisms in genes involved in folate metabolism and colorectal neoplasia: a HuGE review. Am J Epidemiol 159, 423-443.

6. Rozen R (1997) Genetic predisposition to hyperhomocysteinemia: deficiency of methylenetetrahydrofolate reductase (MTHFR). Thromb Haemost 78, 523-526.

7. Frosst P, Blom HJ, Milos R, et al. (1995) A candidate genetic risk factor for vascular disease: a common mutation in methylenetetrahydrofolate reductase. Nat Genet 10, 111-113.

8. Ma J, Stampfer MJ, Christensen B, et al. (1999) A polymorphism of the methionine synthase gene: assocation with plasma folate, vitamin $\mathrm{B}_{12}$, homocyst(e)ine, and colorectal cancer risk. Cancer Epidemiol Biomarkers Prev 8, 825-829.

9. Guenther BD, Sheppard CA, Tran P, Rozen R, Matthews RG \& Ludwig ML (1999) The structure and properties of methylenetetrahydrofolate reductase from Escherichia coli suggest how folate ameliorates human hyperhomocystenemia. Nat Struct Biol 6, 359-365.

10. Yamada K, Chen Z, Rozen R \& Mathews RG (2001) Effects of common polymorphisms on the properties of recombinant human methylenetetrahydrofolate reductase. Proc Natl Acad Sci U S A 98, 14853-14858.

11. Brockton NT (2006) Localized depletion: the key to colorectal cancer risk mediated by MTHFR genotype and folate? Cancer Causes Control 17, 1005-1016.

12. van der Put NMJ, Gabreels F, Stevens EMB, Smeitink JA, Trijbels FJ, Eskes TK, van den Heuvel LP \& Blom HJ (1998) A second common mutation in the methylenetetrahydrofolate reductase gene: an additional risk factor for neural-tube defects? Am J Human Genet 62, 1044-1051.

13. Chango A, Boisson F, Barbe F, et al. (2000) The effect of 677C-T and 1298A-C mutations on plasma homocysteine and 5,10-methylenetetrahydrofolate reductase activity in healthy subjects. Br J Nutr 83, 593-596.

14. Hubner RA \& Houlston RS (2006) MTHFR C677T and colorectal cancer risk: a meta-analysis of 25 populations. Int $J$ Cancer 120, 1027-1035.

15. Huang Y, Han S, Li Y, Mao Y \& Xie Y (2007) Different roles of MTHFR C677T and A1298C polymorphisms in colorectal adenoma and colorectal cancer: a meta-analysis. J Human Genet 52, 73-85.

16. Food Standards Agency (2003) National Diet and Nutrition Survey http://www.food.gov.uk/science/101717/ndnsdocuments/ (accessed 29 July 2006).

17. Bates CJ, Mansoor MA, van der Pols J, Prentice A, Cole TJ \& Finch S (1997) Plasma total homocysteine in a representative sample of 972 British men and women aged 65 and over. Eur J Clin Nutr 51, 691-697.

18. Erens B (2000) Alcohol consumption. In The Scottish Health Survey 1998, vol. 1, chapter 9 [A Shaw, A McMunn and J Fields, editors]. Edinburgh: The Stationery Office.

19. Boreham R (2000) Smoking. In The Scottish Health Survey, 1998, vol. 1, chapter 8 [A Shaw, A McMunn and J Fields, editors]. Edinburgh: The Stationery Office.

20. Parkin DM, Whelan SL, Ferlay J, Teppo L \& Thomas DB (2002) Cancer Incidence in Five Continents, vol. VIII, Lyon: IARC.

21. Garten MJ, Abdalla MI, Reid DM \& Russell IT (1996) Estimating the point accuracy of population registers using capturerecapture methods in Scotland. J Epidemiol Comm Health 50, 99-103.

22. University of Aberdeen (2006) Scottish Collaborative Group Food Frequency Questionnaire http://www.abdn.ac.uk/deom/ ffq/index.htm (accessed 29 July 2006).

23. Masson LF, McNeill G, Tomany JO, Simpson JA, Peace HS, Wei L, Grubb DA \& Bolton-Smith C (2003) Statistical approaches for assessing the relative validity of a food frequency questionnaire: use of correlation coefficients and the $\mathrm{k}$ statistic. Public Health Nutr 6, 313-321.

24. van der Put NMJ \& Blom HJ (2000) Reply to Donnelly. Am J Hum Genet 66, 744-745.

25. Holland B, McCance RA \& Widdowson EH (1991) McCance and Widdowson's The Composition of Foods, 5th ed., Cambridge, UK: Royal Society of Chemistry.

26. Willett W (1998) Nutritional Epidemiology, 2nd ed., New York: Oxford University Press.

27. Hseih CC, Maisonneuve P, Boyle P, Macfarlane GJ \& Robertson C (1991) Analysis of quantitative data by quantiles in epidemiologic studies: classification according to cases, noncases, or all subjects? Epidemiology 2, 137-140.

28. Breslow NE \& Day NE (1980) Statistical Methods in Cancer Research, vol. 1 - The Analysis of Case-control Studies. IARC Scientific Publication no. 32, vol. 1, Lyon: IARC.

29. Hosmer DW \& Lemeshow S (1989) Applied Logistic Regression. New York: Wiley.

30. Macfarlane TV, Gray RJM, Kincey J \& Worthington HV (2001) Factors associated with the temporomandibular disorder, pain dysfunction syndrome (PDS): Manchester case-control study. Oral Dis 7, 321-330.

31. Sharp L (2005) Folate and Genetic Variation in Folate Metabolism in the Aetiology of Colorectal Cancer. PhD Thesis, University of Aberdeen.

32. Little J, Sharp L, Masson LF, Brockton NT, Cotton SC, Haites NE \& Cassidy J (2006) Colorectal cancer and genetic polymorphisms of CYP1A1, GSTM1 and GSTT1: a case-control study in the Grampian region of Scotland. Int $J$ Cancer 119, 2155-2164.

33. Botto LD \& Yang Q (2000) 5,10 Methylenetetrahydrofolate reductase gene variants and congenital anomalies: a HuGE review. Am J Epidemiol 151, 862-877.

34. Sharp L, Little J, Schofield AC, Pavlidou E, Cotton SC, Miedzybrodzka Z, Baird JO, Haites NE, Heys SD \& Grubb DA (2002) Folate and breast cancer: the role of polymorphisms in methylenetetrahydrofolate reductase (MTHFR). Cancer Lett 181, 65-71.

35. Little J, Bradley L, Bray MS, et al. (2002) Reporting, appraising, and integrating data on genotype prevalence and gene-disease associations. Am J Epidemiol 156, 300-310.

36. Ma J, Stampfer MJ, Giovannucci E, Artigas C, Hunter DJ, Fuchs C, Willett WC, Selhub J, Hennekens CH \& Rozen R (1997) Methylenetetrahydrofolate reductase polymorphism, dietary interactions and risk of colorectal cancer. Cancer Res $\mathbf{5 7}, 1098-1102$ 
37. Scottish Executive (2001) Office of the Chief Statistician. Analysis of Ethnicity in the 2001 Census - Summary Report http://www.scotland.gov.uk/library5/social/aescr-00.asp (accessed 23 July 2005).

38. Khlat M, Cazes MH, Genin E \& Guiguet M (2004) Robustness of case-control studies of genetic factors to population stratification: magnitude of bias and type I error. Cancer Epidemiol Biomarkers Prev 13, 1660-1664.

39. Van Guelpen B, Hultdin J, Johansson I, Hallmans G, Stenling R, Riboli E, Winkvist A \& Palmqvist R (2006) Low folate levels may protect against colorectal cancer. Gut 55, 1461-1466.

40. Wei EK, Giovannucci E, Wu K, Rosner B, Fuchs CS, Willett WC \& Colditz GA (2004) Comparison of risk factors for colon and rectal cancer. Int J Cancer 108, 433-442.

41. Larsson SC, Giovannucci E \& Wolk A (2005) A prospective study of dietary folate intake and risk of colorectal cancer: modification by caffeine intake and cigarette smoking. Cancer Epidemiol Biomarkers Prev 14, 740-743.

42. Herbert V (1987) Recommended dietary intakes (RDI) of folate in humans. Am J Clin Nutr 45, 661-670.

43. Yang Q \& Erickson JD (2003) Influence of reporting error on the relation between blood folate concentrations and reported folic acid-containing dietary supplement use among reproductive-aged women in the United States. Am J Clin Nutr 77, 196-203.

44. Freudenheim JL, Graham S, Marshall JR, Haughey BP, Cholewinski S \& Wilkinson G (1991) Folate intake and carcinogenesis of the colon and rectum. Int J Epidemiol 20, 368-374.

45. Meyer F \& White E (1993) Alcohol and nutrients in relation to colon cancer in middle-aged adults. Am $J$ Epidemiol 138, 225-236.

46. Ferraroni M, La Vecchia C, D'Avanzo B, Negri E, Franceschi S \& Decarli A (1994) Selected micronutrient intake and the risk of colorectal cancer. Br J Cancer 70, 1150-1155.

47. Tseng M, Murray SC, Kupper LL \& Sandler RS (1996) Micronutrients and the risk of colorectal adenomas. Am J Epidemiol 144, 1005-1014

48. Slattery ML, Schaffer D, Edwards SL, Ma KN \& Potter JD (1997) Are dietary factors involved in DNA methylation associated with colon cancer? Nutr Cancer 28, 52-62.

49. White E, Shannon JS \& Patterson RE (1997) Relationship between vitamin and calcium supplement use and colon cancer. Cancer Epidemiol Biomarkers Prev 6, 769-774.

50. Giovannucci E, Rimm EB, Ascherio A, Stampfer MJ, Colditz GA \& Willett WC (1995) Alcohol, low-methionine-low-folate diets, and risk of colon cancer in men. J Natl Cancer Inst 87, 265-273.

51. Great British National Food Survey Committee, Ministry of Agriculture, Fisheries and Food (1999) National Food Survey 1998 Annual Report on Food Expenditure, Consumption and Nutrient Intakes. London: The Stationery Office.

52. Bailey LB (2004) Folate and vitamin $B_{12}$ recommended intakes and status in the United States. Nutr Rev 62, S14-S20.

53. Finch S, Doyle W, Lowe C, Bates CJ, Prentice A, Smithers G \& Clarke PC (1998) National Diet and Nutrition Survey: People Aged 65 and Over. 1. Report of the Diet and Nutrition Survey. London: The Stationery Office.

54. Keku T, Millikan R, Worley K, Winkel S, Eaton A, Biscocho L, Martin C \& Sandler R (2002) 5,10-Methylenetetrahydrofolate reductase codon 677 and 1298 polymorphisms and colon cancer in African Americans and whites. Cancer Epidemiol Biomarkers Prev 11, 1611-1621.

55. Giovannucci E, Stampfer MJ, Colditz GA, Hunter DJ, Fuchs C, Rosner BA, Speizer FE \& Willett WC (1998) Multivitamin use, folate, and colon cancer in women in the Nurses' Health Study. Ann Intern Med 129, 517-524.
56. Kato I, Dnistrian AM, Schwartz M, Toniolo P, Koenig K, Shore RE, Akhmedkhanov A, Zeleniuch-Jacquotte A \& Riboli E (1999) Serum folate, homocysteine and colorectal cancer risk in women: a nested case-control study. $B r J$ Cancer 79, 1917-1921.

57. Harnack L, Jacobs DR, Nicodemus K, Lazovich D, Anderson K \& Folsom AR (2002) Relationship of folate, vitamin $B_{6}$, vitamin $\mathrm{B}_{12}$, and methionine intake to incidence of colorectal cancers. Nutr Cancer 43, 152-158.

58. La Vecchia C, Negri E, Pelucchi C \& Franceschi S (2002) Dietary folate and colorectal cancer. Int J Cancer 102, 545-547.

59. Terry P, Jain M, Miller AB, Howe GR \& Rohan TE (2002) Dietary intake of folic acid and colorectal cancer risk in a cohort of women. Int J Cancer 97, 864-867.

60. Su LJ \& Arab L (2001) Nutritional status of folate and colon cancer risk: evidence from NHANES I epidemiologic followup study. Ann Epidemiol 11, 65-72.

61. Ogino S \& Wilson RB (2003) Genotype and haplotype distributions of MTHFR 677C $>\mathrm{T}$ and 1298A $>\mathrm{C}$ single nucleotide polymorphisms: a meta-analysis. J Human Genet 48, 1-7.

62. Chen J, Giovannucci E, Kelsey K, Rimm EB, Stampfer MJ, Colditz GA, Spiegelman D, Willett WC \& Hunter DJ (1996) A methylenetetrahydrofolate reductase polymorphism and the risk of colorectal cancer. Cancer Res 56, 4862-4864.

63. Le Marchand L, Donlon T, Hankin JH, Kolonel LN, Wilkens LR \& Seifried A (2002) B-vitamin intake, metabolic genes, and colorectal cancer risk (United States). Cancer Causes Control 13, 239-248.

64. Slattery ML, Potter JD, Samowitz W, Schaffe D \& Leppert M (1999) Methylenetetrahydrofolate reductase, diet, and risk of colon cancer. Cancer Epidemiol Biomarkers Prev 8, $513-518$.

65. Chen J, Ma J, Stampfer MJ, Palomeque C, Selhub J \& Hunter D (2002) J. Linkage disequilibrium between the $677 \mathrm{C}>\mathrm{T}$ and $1298 \mathrm{~A}>\mathrm{C}$ polymorphisms in human methylenetetrahydrofolate reductase gene and their contributions to risk of colorectal cancer. Pharmacogenetics 12, 339-342.

66. Little J, Sharp L, Duthie S \& Narayanan S (2003) Colon cancer and genetic variation in folate metabolism: the clinical bottom line. J Nutr 133, 3758S-3766S.

67. Narayanan S, McConnell J, Little J, Sharp L, Piyathilake CJ, Powers H, Basten G \& Duthie SJ (2004) Associations between two common variants C677T and A1298C in the methylenetetrahydrofolate reductase gene and measures of folate metabolism and DNA stability (strand breaks, misincorporated uracil, and DNA methylation status) in human lymphocytes in vivo. Cancer Epidemiol Biomarkers Prev 13, $1436-1443$.

68. Crott JW, Mashiyama ST, Ames BN \& Fenech MF (2001) Methylenetetrahydrofolate reductase C677T polymorphism does not alter folic acid deficiency-induced uracil incorporation into primary human lymphocyte DNA in vitro. Carcinogenesis 22, 1019-1025.

69. Andreassi MG, Botto N, Cocci F, Battaglia D, Antonioli E, Masetti S, Manfredi S, Colombo MG, Biagini A \& Clerico A (2003) Methylenetetrahydrofolate reductase gene C677T polymorphism, homocysteine, vitamin $\mathrm{B}_{12}$, and DNA damage in coronary artery disease. Hum Genet 112, 171-177.

70. Zijno A, Andreoli C, Leopardi P, Marcon F, Rossi S, Caiola S, Verdina A, Galati R, Cafolla A \& Crebelli R (2003) Folate status, metabolic genotype, and biomarkers of genotoxicity in healthy subjects. Carcinogenesis 24, 1097-1103.

71. Kimura $\mathrm{M}$, Umegaki K, Higuchi $\mathrm{M}$, Thomas $\mathrm{P} \&$ Fenech $\mathrm{M}$ (2004) Methylenetetrahydrofolate reductase C677T polymorphism, folic acid and riboflavin are important determinants of genome stability in cultured human lymphocytes. J Nutr 134, $48-56$. 
72. Friso S, Girelli D, Trabetti E, Olivieri O, Guarini $\mathrm{P}$, Pignatti PF, Corrocher R \& Choi SW (2005) The MTHFR 1298A > C polymorphism and genomic DNA methylation in human lymphocytes. Cancer Epidemiol Biomarkers Prev 14, 938-943.

73. Bagley PJ \& Selhub J (1998) A common mutation in the methylenetetrahydrofolate reductase gene is associated with an accumulation of formylated tetrahydrofolates in red blood cells. Proc Natl Acad Sci USA 95, 13217-13220.

74. Kawakami K, Ruszkiewicz A, Bennett G, Moore J, Watanabe G \& Iacopetta B (2003) The folate pool in colorectal cancers is associated with DNA hypermethylation and with a polymorphism in methylenetetrahydrofolate reductase. Clin Cancer Res $\mathbf{9}$, $5860-5865$. 